\title{
Reduction of pain thresholds in fibromyalgia after very low-intensity magnetic stimulation: A double-blinded, randomized placebo-controlled clinical trial
}

\author{
Ceferino Maestú $\mathrm{PhD}^{1,2}$, Manuel Blanco $\mathrm{MD}^{1,3}$, Angel Nevado $\mathrm{PhD}^{4,5}$, Julia Romero $\mathrm{MD}^{3}$, Patricia Rodríguez-Rubio $\mathrm{MD}^{3}$, \\ Javier Galindo $M D^{3}$, Juan Bautista Lorite $M D^{3}$, Francisco de las Morenas $M D^{3}$, Pedro Fernández-Argüelles $M^{6}$
}

\begin{abstract}
C Maestú, M Blanco, A Nevado, et al. Reduction of pain thresholds in fibromyalgia after very low-intensity magnetic stimulation: A double-blinded, randomized placebo-controlled clinical trial. Pain Res Manag 2013;18(6):e101-e106.
\end{abstract}

BACKGROUND: Exposure to electromagnetic fields has been reported to have analgesic and antinociceptive effects in several organisms.

OBJECTIVE: To test the effect of very low-intensity transcranial magnetic stimulation on symptoms associated with fibromyalgia syndrome.

METHODS: A double-blinded, placebo-controlled clinical trial was performed in the Sagrado Corazón Hospital, Seville, Spain. Female fibromyalgia patients ( 22 to 50 years of age) were randomly assigned to either a stimulation group or a sham group. The stimulation group $(n=28)$ was stimulated using $8 \mathrm{~Hz}$ pulsed magnetic fields of very low intensity, while the sham group $(n=26)$ underwent the same protocol without stimulation. Pressure pain thresholds before and after stimulation were determined using an algometer during the eight consecutive weekly sessions of the trial. In addition, blood serotonin levels were measured and patients completed questionnaires to monitor symptom evolution.

RESULTS: A repeated-measures ANOVA indicated statistically significant improvement in the stimulation group compared with the control group with respect to somatosensory pain thresholds, ability to perform daily activities, perceived chronic pain and sleep quality. While improvement in pain thresholds was apparent after the first stimulation session, improvement in the other three measures occurred after the sixth week. No significant between-group differences were observed in scores of depression, fatigue, severity of headaches or serotonin levels. No adverse side effects were reported in any of the patients.

CONCLUSIONS: Very low-intensity magnetic stimulation may represent a safe and effective treatment for chronic pain and other symptoms associated with fibromyalgia.

Key Words: Analgesic effect; Fibromyalgia; Low intensity; Transcranial magnetic stimulation

$\mathrm{T}$ here is increasing evidence of the effect of low-intensity electromagnetic fields (EMF) on different aspects of animal and human physiology and behaviour. EMF have been shown to affect the synaptic activity of snail single neurons (1) and the neuronal activity in rat hippocampal slice preparations (2). Analgesic effects of EMF on snails (3), mice $(4,5)$ and rats $(6)$ have also been described. Although exposure of animals to low-intensity magnetic fields has typically been performed in the $\mu \mathrm{T}$ range, amplitudes in the nT range in electromagnetically shielded environments (7) have also been shown to affect nociception in mice. In humans, the effect of EMF on pain severity has also been investigated in a variety of conditions (8) including fibromyalgia $(9,10)$.

Fibromyalgia syndrome (FMS) is characterized by chronic widespread musculoskeletal pain, fatigue, nonrestorative sleep, and concentration and memory deficits $(11,12)$. The prevalence of fibromyalgia is approximately $2.0 \%$ in both sexes, $3.4 \%$ among women and $0.5 \%$ among men (13). Studies of experimentally induced pain demonstrate

\section{La réduction des seuils de douleur en fibromyalgie après une stimulation magnétique de très faible intensité : un essai aléatoire clinique à double insu contrôlé contre placebo}

HISTORIQUE : L'exposition aux champs électromagnétiques a des effets analgésiques et antinociceptifs sur plusieurs organismes.

OBJECTIF : Vérifier l'effet d'une stimulation magnétique transcrânienne de très faible intensité sur les symptômes associés au syndrome fibromyalgique. MÉTHODOLOGIE : Les chercheurs ont effectué un essai clinique à double insu contrôlé contre placebo à l'hôpital Sagrado Corazón de Séville, en Espagne. Les patientes atteintes de fibromyalgie (de 22 à 50 ans) ont été réparties de manière aléatoire entre un groupe de stimulation et un groupe témoin. Le groupe de stimulation $(\mathrm{n}=28)$ a été stimulé au moyen de champs magnétiques de $8 \mathrm{~Hz}$ de très faible intensité, tandis que le groupe témoin $(n=26)$ a subi le même protocole sans stimulation. Les seuils de pression à la douleur avant et après la stimulation ont été déterminés au moyen d'un algomètre pendant les séances de huit semaines consécutives de l'essai. De plus, les taux de sérotonine dans le sang ont été mesurés et les patients ont rempli des questionnaires pour vérifier l'évolution des symptômes.

RÉSULTATS : Des mesures de variance répétées ont démontré une amélioration statistiquement significative du groupe de stimulation par rapport au groupe témoin à l'égard des seuils de douleur somatosensorielle, de la capacité d'effectuer les activités quotidiennes et de la qualité du sommeil. Même si l'amélioration du seuil de douleur était apparente après la première séance de stimulation, les trois autres mesures se sont améliorées au bout de la sixième semaine. Les chercheurs n'ont observé aucune différence significative entre les groupes pour ce qui est des indices de dépression, de fatigue, de gravité des céphalées ou des taux de sérotonine. Aucun patient n'a déclaré d'effets secondaires indésirables.

CONCLUSIONS : Une stimulation magnétique de très faible intensité peut représenter un traitement sécuritaire et efficace de la douleur chronique et d'autres symptômes associés à la fibromyalgie.

that these patients have a lower pain threshold because lower-intensity stimuli are needed to evoke pain (14). The decrease in pain threshold is particularly evident at a number of 'tender points' (11). Serotonin levels in blood have also been found to be altered in FMS (15). The efficacy of current pharmacological treatments of FMS is limited (16).

Although the precise pathophysiological basis of the disease remains to be elucidated, recent studies have demonstrated altered brain processing of nociceptive information in FMS patients $(17,18)$, which may result from hyperexcitability of the central nervous system (19-21). Functional magnetic resonance imaging studies have shown an increased brain response in areas activated by painful stimuli, the amount of stimulation necessary to activate these areas in fibromyalgia patients being lower than in healthy individuals (19). Electroencephalographic components evoked by nociceptive stimuli have higher amplitude and longer duration (22), and habituation responses to repetitive stimuli are delayed in FMS patients (23).

${ }^{1}$ Humanism and Science Foundation; ${ }^{2}$ Centre for Biomedical Technology, Technical University of Madrid, Madrid; ${ }^{3}$ Sagrado Corazón Hospital, Seville;

${ }^{4}$ Laboratory for Cognitive and Computational Neuroscience, Centre for Biomedical Technology, Technical University of Madrid and Complutense

University of Madrid; ${ }^{5}$ Basic Psychology Department II, Complutense University of Madrid, Madrid; ${ }^{6}$ Virgen del Rocio Hospital, Seville, Spain

Correspondence: Dr Ceferino Maestú, Centro de Tecnología Biomédica (CTB), Campus de Montegancedo, 28223 Pozuelo de Alarcón, Madrid,

Spain. Telephone 34-91452-4900 ext 24655, fax 34-91336-6828, e-mail ceferino.maestu@ctb.upm.es 


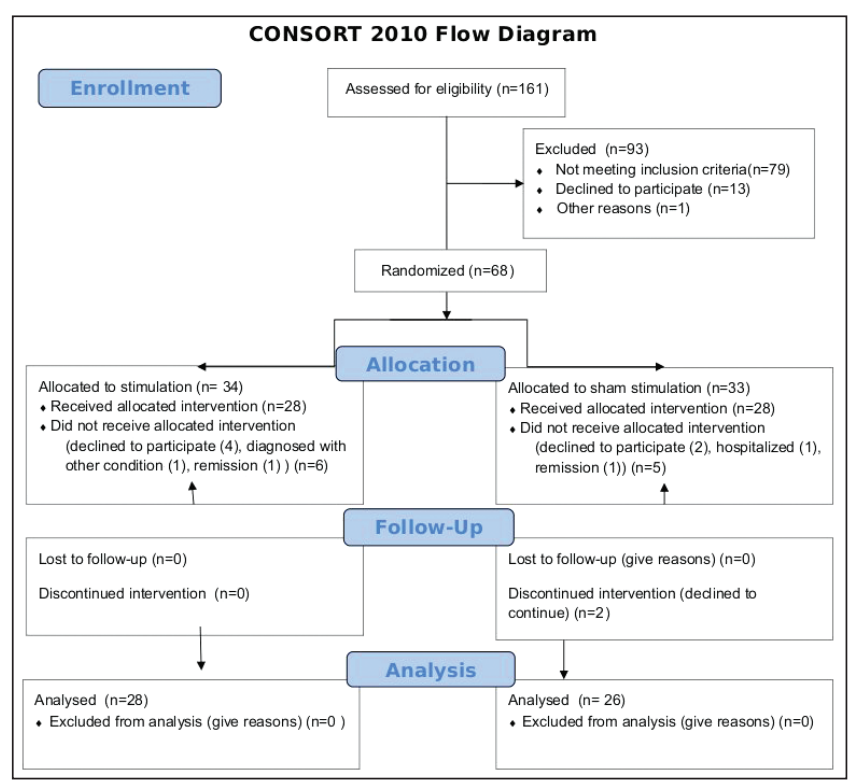

Figure 1) Patient flow diagram specifying patient numbers for each of the assessment steps

A number of studies have shown that high-intensity repetitive transcranial magnetic stimulation (TMS) can be effective for the treatment of FMS (24-28). Marlow et al (29) conducted a review of these and transcranial direct current stimulation studies. Conventional repetitive TMS induces peak magnetic fields in the order of $1 \mathrm{~T}$ to $3 \mathrm{~T}$. The use of very low-intensity TMS, as in the present clinical trial, which was in the order of $\mathrm{nT}$, is less well researched. A previous clinical trial (10) reported improvement in subjective pain scores in fibromyalgia patients after low-intensity magnetic stimulation using a specific protocol, which approached statistical significance compared with sham stimulation. In the present clinical trial, a new method of very low-intensity TMS was used.

\section{OBJECTIVES}

The present double-blinded clinical trial was designed to test the effect of very low-intensity TMS on several symptoms associated with FMS. Objectively measured variables were pain thresholds to somatosensory stimulation and blood serotonin levels. In addition, participants completed questionnaires rating levels of fatigue, anxiety, depression, chronic pain, sleep quality and ability to perform activities.

\section{METHODS}

\section{Patients}

Subjects were informed about the nature of the study verbally and using printed leaflets, and informed consent was obtained from all participants. The protocol was approved by the Ethics Committee of Virgen Macarena Hospital (Seville, Spain) and by the Spanish Drug and Sanitary Product Agency (Agencia Española del Medicamento y Producto Sanitario [AEMPS], www.aemps.es/en/, trial number 275/06/ EC), and conformed to the Declaration of Helsinki. The AEMPS also approved the final report of the clinical trial, titled Prueba de concepto de eficacia y seguridad de la estimulación magnética de baja intensidad sobre la enfermedad fibromiálgica (Proof of concept for the efficacy and security of low-intensity magnetic stimulation in fibromyalgia). A doubleblinded experimental design was used, such that neither the patients nor the experimenters knew which of the groups was being stimulated. Inclusion criteria included the following: patients had received a diagnosis of fibromyalgia according to the criteria of the American Association of Rheumatology such that they experienced widespread pain and tenderness at 11 or more of 18 specific tender point sites; patients had to have been diagnosed at least 12 months before the beginning of the clinical trial; and patients had to be female (because fibromyalgia is more prevalent in women) and between 20 and 60 years of age. Exclusion criteria were the following: currently pregnant; having been diagnosed with a medical condition other than FMS; or using a pacemaker or other metal implant, to avoid potential heating. Patients diagnosed with other medical conditions were excluded to minimize the possibility that potential treatment-related symptom changes were associated with a condition that was not fibromyalgia. Patients were asked to discontinue any medication except, possibly, acetaminophen or bromazepam, one month before the start of the trial. Patients for whom this was not possible were excluded from the study. Blood tests measuring blood cell count, acute phase reactants, erythrocyte sedimentation rate, serum electrolyte levels, glycemic index, liver and thyroid function, and a number of antibodies were performed before the trial. Results had to be normal or negative for patients to be included in the study. Patients were recruited from members of fibromyalgia associations in the Seville area, and evaluated for eligibility by three experienced physicians from March to May 2006 at the Sagrado Corazón Hospital (Seville, Spain). To obtain a sample size that was as large as possible, all patients who accepted the invitation to participate in the clinical trial during the predefined recruitment period were assessed for eligibility. A total of 161 female patients were recruited and assessed for eligibility. Of these, 67 patients fulfilling the inclusion and exclusion criteria agreed to participate and, following a parallel design, were randomly assigned to either the stimulation group $(n=34)$ or the sham group $(n=33)$, with a 1:1 allocation ratio. Four externally identical stimulation devices (two of which were capable of producing magnetic fields and two of which were manipulated so that no field was produced) were provided to the notary before randomization. A public notary performed the 1:1 random allocation, randomly labelled each stimulation device with the letter of the group they corresponded to (either A or B) and sealed them. Neither the experimenters nor the patients had access to the results of the randomization until all trial outcome measures had concluded. The individuals responsible for delivering the actual and sham stimulation knew which group the patients belonged to, but not which group was actually being stimulated. Of the 67 patients who were originally assigned to groups, 28 patients in the stimulation group and 26 in the sham group completed the stimulation/sham protocol (Figure 1). Therefore, data from 28 patients from the stimulation group and 26 patients in the sham group were used for the analysis.

The selected patient group had a mean $( \pm$ SD) age of $40.7 \pm 6.7$ years (range 22 to 50 years). The mean weight was $60 \pm 9.3 \mathrm{~kg}$ (range $47 \mathrm{~kg}$ to $83 \mathrm{~kg}$ ) and the mean height was $1.67 \pm 0.08 \mathrm{~m}$ (range $1.50 \mathrm{~m}$ to $1.75 \mathrm{~m}$ ). All patients lived in or near Seville, in southern Spain. Of this group, 18 (33.3\%) had at least a first-degree relative diagnosed with FMS.

Stimulation sessions occurred between June and August of 2006 at the Sagrado Corazón Hospital, Seville. No adverse side effects were reported by any of the patients throughout the course of the clinical trial, nor did they report experiencing any somatosensory, auditory or other sensory phenomena as a result of the stimulation.

\section{Magnetic stimulation}

Stimulation/sham sessions occurred once per week for eight consecutive weeks. Sessions were scheduled in the morning between 09:00 and 12:00, and lasted $20 \mathrm{~min}$. They occurred inside two Faraday cages to reduce environmental electromagnetic interference. One Faraday cage was used for actual stimulation and the other for sham stimulation. As described, all stimulation devices were externally identical. Neither patients nor researchers knew which was which. Stimulation was delivered via a custom-built magnetic stimulator (30). Briefly, a flexible electroencephalography (EEG) cap with 33 stimulation coils was placed over the patient's head. The stimulation coils were distributed evenly in an attempt to maximize the distance between the EEG electrodes, arranged according to the 10-20 system (31), to enable the possibility of performing EEG recordings while stimulation was being 


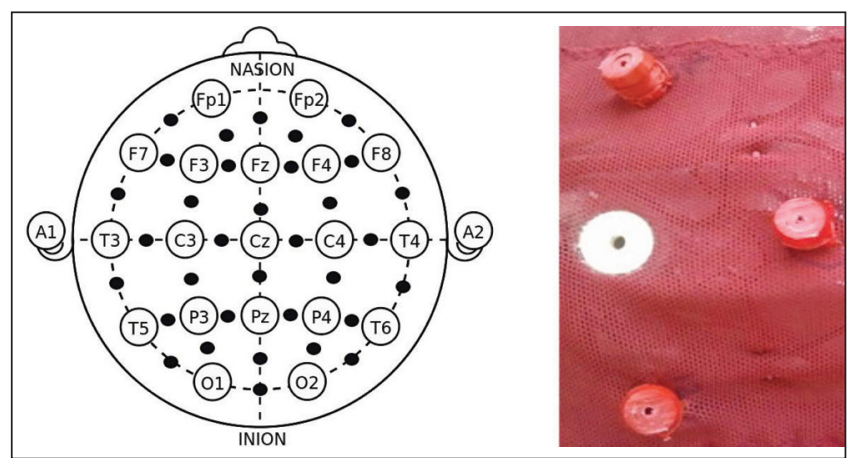

Figure 2) The left panel indicates the location of the stimulation coils (black circles) in relation to the electroencephalography 10-20 system. The right panel shows details of three coils (red) around an electroencephalography electrode (white)

performed in future studies. Therefore, stimulation was general rather than focal. Figure 2 shows the locations and appearance of the stimulation coils. Each coil had seven loops and was $2 \mathrm{~cm}$ in diameter. A digital electronic generator fed the same oscillating current of intensity to the 27 coils. The current amplitude was $545 \mu \mathrm{A}$. Each coil produces a magnetic field of approximately $43 \mathrm{nT}$ at a distance of $1 \mathrm{~cm}$ and $0.9 \mathrm{nT}$ at a distance of $4 \mathrm{~cm}$. A low-frequency $(8 \mathrm{~Hz})$ square function was used. This frequency was chosen because pilot data suggested that it could be effective for treating fibromyalgia. Figure 3 shows a ocilloscope measurement of the voltage applied to the coils. A frequencimeter registered an applied frequency of $8.00005 \mathrm{~Hz}$, which is very close to the intended frequency. Figure 3 shows that the relative fluctuations in voltage (noise) around the theoretical square function to be applied were approximately $3 \%$. The present stimulation device differed from the protocol used by Thomas et al (10) in that stimulation was less localized and signals were stationary (see Discussion for details).

It should be noted that very low-intensity magnetic stimulation was used. Unlike high-intensity TMS, this stimulation system does not produce any noise. No perceptible effects other than potentially the main and secondary effects object of investigation were reported by either patients or researchers.

\section{Outcome measures}

The primary outcome measures were the pain thresholds at 18 sensitive (tender) points, which were determined using an algometer before and after each of the eight weekly stimulation sessions. Pain thresholds, measured in units of pressure $\left(\mathrm{kg} / \mathrm{cm}^{2}\right)$, were obtained by continuously increasing the pressure exerted by the algometer until the patient reported that it was starting to feel painful. The median pain threshold value across the 18 sensitive points was subsequently calculated. Secondary outcome measures were blood serotonin levels and self-reported ratings of specific symptoms. Serotonin levels were measured in blood before week 1 and after weeks 4 and 8 . The rest of the variables were measured using a self-reported questionnaire in which patients rated on a visual analogue scale (ranging from 0 to 10 ) how they felt the previous week with respect to the following items: ability to perform daily activities, perceived chronic pain intensity, fatigue, anxiety, depression, sleep quality and severity of headaches. The questionnaire was adapted from the Fibromyalgia Impact Questionnaire (32). The ability to perform daily activities comprised nine different questionnaire items: shopping; doing the laundry; preparing meals; doing the washing-up; vacuum-cleaning; making the bed; going upstairs; visiting a friend; and looking after plants. The overall ability to perform daily activities was established by calculating the median score across tasks. Similarly, sleep quality comprised two questionnaire items: how good their sleep was and how they felt in the morning. Pain thresholds were chosen as the primary outcome because the fact that

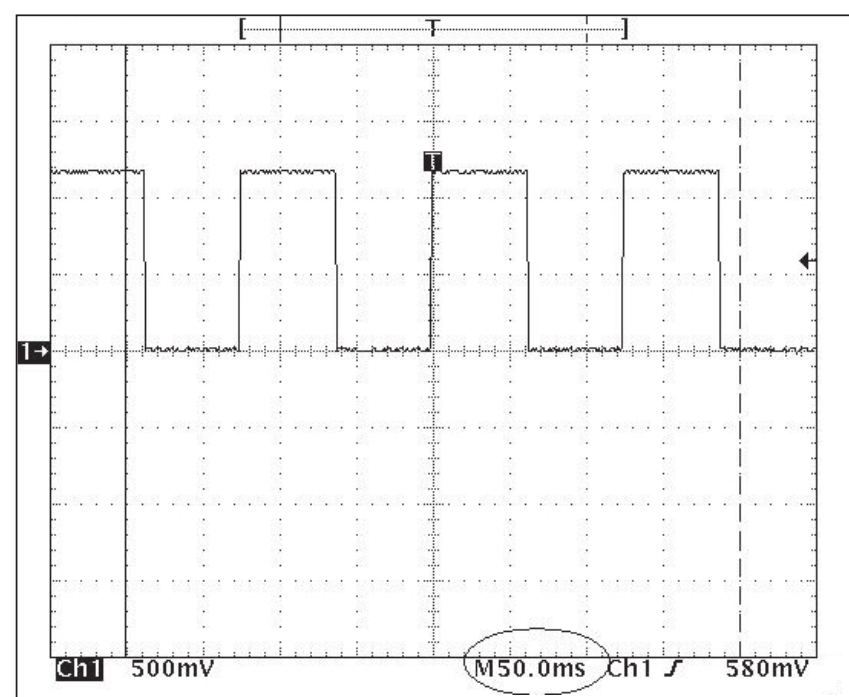

Figure 3) Oscilloscope capture of the voltage applied to the coils. Dotted lines indicate $0.5 \mathrm{~V}$. The reading of approximately $1.2 \mathrm{~V}$ corresponds to an applied current of $1.2 \mathrm{~V} / 2200 \Omega=545 \mu \mathrm{A}$

values are read from an algometer by a researcher makes them less subjective than self-reporting questionnaires.

\section{Statistical analysis}

The different scores were introduced into a two-way repeatedmeasures ANOVA. Time (weeks) $\times$ group (actual and sham stimulation) interactions were considered. Time $\times$ group interactions were evaluated globally by taking into account the entire time period of eight weeks. In addition, the interaction term for individual weeks was evaluated post hoc by comparing each timepoint with the values before week 1 . Statistically significant interaction terms indicate that the time-dependant evolution for the stimulation group was significantly different from the sham group. In the figures, variables for which the interaction term was significant $(\mathrm{P}<0.05)$ globally for the entire time-period are indicated with an asterisk $(*)$ in the title and are framed with a thicker line. Individual weeks for which the evolution from values before week 1 was significantly different between actual and sham stimulation $(\mathrm{P}<0.05)$ have the corresponding value for the stimulation curve depicted in red; otherwise, they are shown in black. Although the post hoc analysis is not warranted for variables that showed no significant differences at the global level, the same convention is used for all measures for illustrative purposes. The analysis was performed using in-house MATLAB software (Mathworks, USA).

\section{RESULTS}

The evolution of pain thresholds is presented in Figure 4. When the entire time period of eight weeks was considered, the increase in pain threshold was significantly larger for the stimulation group $(\mathrm{P}=0.01)$. At the level of individual timepoints, all timepoints showed significant differences, with the exception of four instances corresponding to baseline (before treatment began) and before stimulation at weeks 2 , 4 and 8 . In general, no significant between-group differences were found at baseline for any of the obtained measures, as expected from a random allocation into sham and stimulation groups. For all figures, curves indicate the mean and error bars indicate the SEM across patients.

Significant global improvement in the ability to perform daily activities $(\mathrm{P}=0.03)$ and sleep quality $(\mathrm{P}=0.04)$, and a decrease in perceived pain $(\mathrm{P}=0.02)$ were also observed (Figure 5$)$ when comparing the two groups. Analysis of individual weeks indicated that these changes occurred after week 6 for the three variables. No significant global changes were found for fatigue, anxiety and depression scores (Figure 5). 


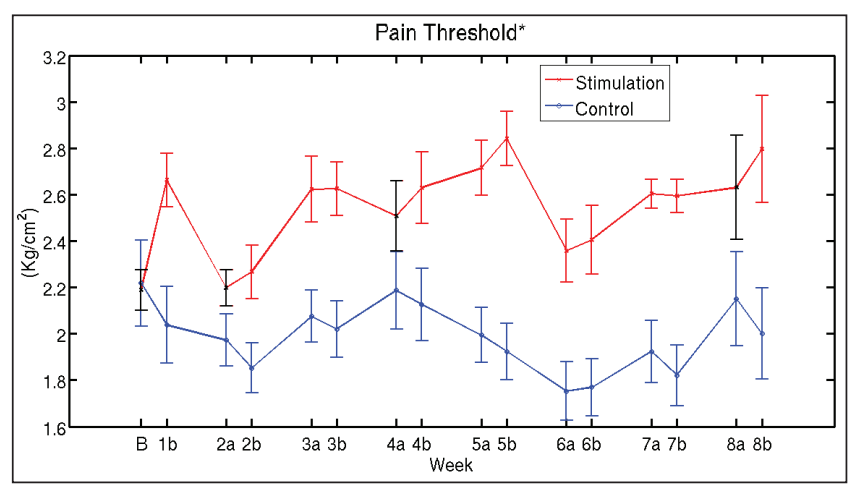

Figure 4) Evolution of pain thresholds. The increase in pain threshold is significantly larger for the stimulation group compared with the control group (time $\times$ group interaction, $P=0.01$ ) when the entire time period of eight weeks was considered. Individual weeks for which the evolution from values before week 1 was significantly different between actual and sham stimulation $(P<0.05)$ have the corresponding value for the stimulation curve depicted in red; otherwise they are shown in black. Curves indicate the mean and error bars indicate the SEM across patients. On the time axis, $B$ denotes baseline (before start of treatment) and $a$ and $b$ indicate time instants before and after treatment, respectively, for each week

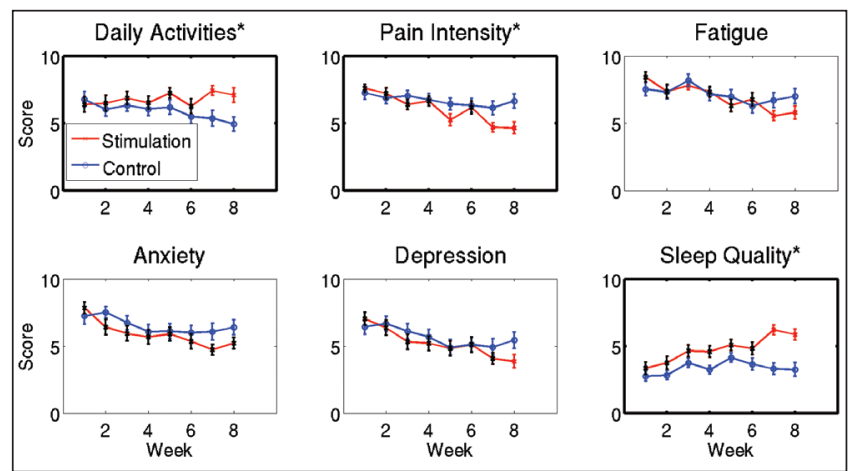

Figure 5) Equivalent visual scale scores. Curves indicate the mean and error bars indicate the SEM across patients. Variables for which the time $\times$ group interaction was significant $(P<0.05)$ for the entire time period are highlighted with an asterisk $(*)$ in the title and are framed with a thicker line (ability to perform daily activities $[P=0.03]$, sleep quality $[P=0.04]$ and perceived pain $[P=0.02])$. No significant global changes were found for fatigue, anxiety and depression scores. Individual weeks for which the evolution from values before week 1 was significantly different between actual and sham stimulation (time $\times$ group interaction $P<0.05$ ) have the corresponding bar for the stimulation curve depicted in red; otherwise they are shown in black

No significant changes in severity of headaches at week 8 and serotonin levels at week 4 or 8 were found (Figure 6)

Finally, to obtain an estimate of the effect size, the evolution of pain threshold scores and subjective chronic pain ratings were reexpressed in terms of relative changes (Figure 7). Relative changes were defined as the difference in score between the timepoint considered and the first timepoint, divided by the score at the first timepoint. After week 8 , there was a mean increase of 28\% (95\% bootstrap CI $8 \%$ to $51 \%$ ) across patients in pain thresholds in the stimulation group, compared with a $-10 \%$ change $(95 \%$ bootstrap CI $-29 \%$ to $9 \%)$ in the sham group. The change in perceived chronic pain after eight sessions was $-39 \%$ (95\% bootstrap CI $-51 \%$ to $-29 \%$ ) for the stimulation group, compared with $-8 \%$ ( $95 \%$ bootstrap CI $-26 \%$ to $13 \%)$ in the sham group. Relative changes for other variables are reported in Table 1.

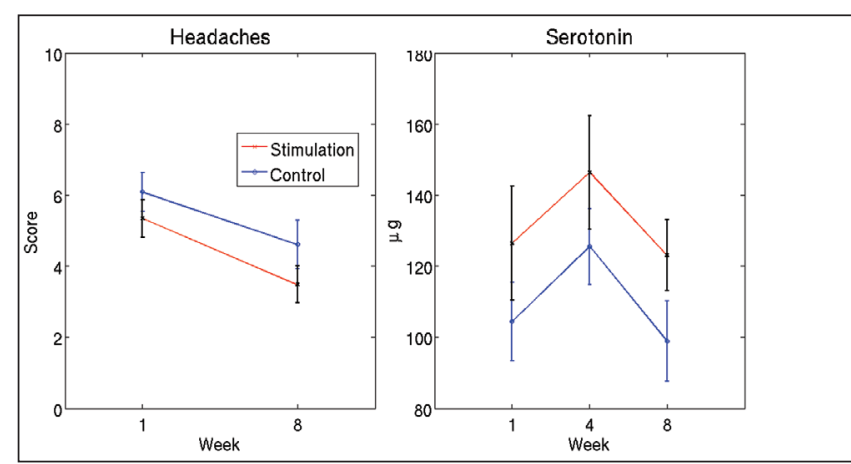

Figure 6) Severity of headaches and serotonin level. Curves indicate the mean and error bars indicate the SEM across patients. No significant changes (time $\times$ group interaction) in severity of headaches at week 8 and serotonin levels at week 4 or 8 were observed

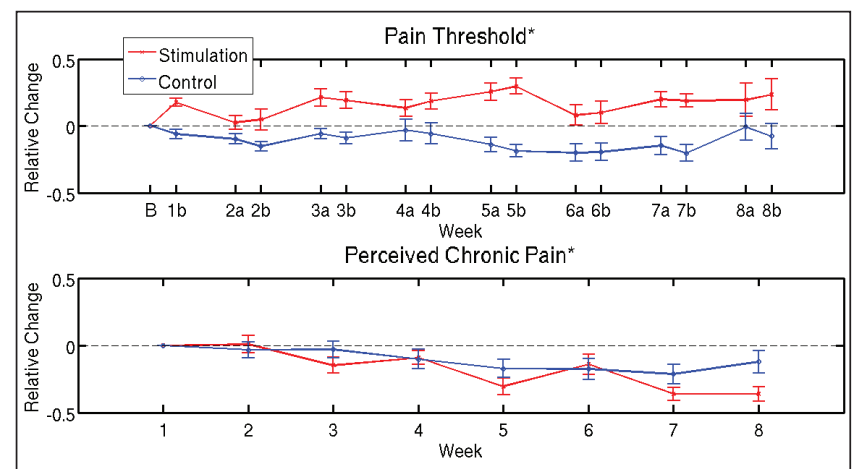

Figure 7) Relative changes in pain thresholds and subjective chronic pain ratings. Evolution of pain ratings in term of relative changes with respect to week 1. The corresponding absolute values are reported in Figure 4 and 5 , respectively. Curves indicate the mean and error bars indicate the SEM across patients. On the time axis, B denotes baseline (before start of treatment) and $a$ and $b$ indicate time instants before and after treatment, respectively, for each week

\section{DISCUSSION}

Fibromyalgia is a prevalent condition that significantly affects the quality of life of patients. Current treatment options exhibit limited efficacy. In the present clinical trial, we investigated whether very lowintensity TMS helps to reduce symptoms. The evolution of pain thresholds during the eight-week period of the trial indicates that very low-intensity TMS was effective in increasing the abnormally low pain thresholds associated with FMS. Improvement in the stimulation group occurred after the first session and was present for most of the eight-week period. After week 6, patients also reported a decrease in subjective chronic pain, an increase in the ability to perform daily activities and an improvement in sleep quality. In contrast, symptoms for which no significant differences were found included fatigue, anxiety and depression scores, severity of headaches and level of serotonin in blood.

The mechanisms by which central nervous exposure to weak electromagnetic fields may have analgesic and antinociceptive effects remain to be elucidated. There is evidence that endogenous opioid systems are affected by magnetic fields (33). Proposed mechanisms of how weak magnetic fields may affect the central nervous system include induced electric currents, magnetite, radical pair combinations and resonance interactions (34-36). The induction of electric currents appears to be an unlikely mechanism given that the induced fields are orders of magnitude lower than the endogenous electric fields present in tissues. Similarly, an important limitation of the magnetite hypothesis is that a connection between magnetite and the nervous system has not been demonstrated. The model most consistent with 
the observed effects of magnetic fields is the interaction between the external magnetic fields and internal resonant systems such as radical pair processes (36).

A previous clinical trial (10) investigated the effect of low-intensity magnetic stimulation on the reduction of self-reported chronic pain scores in fibromyalgia patients. Results indicated an improvement in pain scores that approached statistical significance $(\mathrm{P}=0.06)$. While the general approach and design is similar, differences exist between this previous clinical trial and the present trial. In the present study, group differences were significant $(\mathrm{P}<0.05)$, while in the previous study they were approaching significance $(\mathrm{P}=0.06)$. In the present clinical trial, magnetic fields were applied once per week for $20 \mathrm{~min}$ for eight consecutive weeks, and intensity was in the order of nT. In the previous study, patients underwent two daily sessions of $40 \mathrm{~min}$ for seven consecutive days, and the magnetic fields had an intensity in the order of $\mu \mathrm{T}$. It should be noted, nevertheless, that this same group (7) reported nociceptive effects of magnetic fields in the order of $\mathrm{nT}$ in mice when they were immersed in an electromagnetically shielded environment, as in the present study. Here, stimulation coils were evenly distributed across the cap, while previously a more focal source was used and, therefore, the field was less homogeneous. Finally, a square wave signal was used in the present study, while a signal with a more complex temporal pattern was used in the previous trial. Despite these differences, both trials provide evidence of improvement of pain scores after low-intensity TMS, even if in the previous work the difference was marginally significant $(\mathrm{P}<0.06)$. The fact that these two studies were performed independently and with somewhat differing methodology reinforces the notion that low-intensity TMS can be effective in alleviating the symptoms associated with FMS.

An important question for future studies is what combination of methods/parameters is most effective in reducing FMS symptoms. It has been reported that spatial inhomogeneities in the magnetic field increase its analgesic effect in mice (36). Likewise, the specific temporal pattern of stimulation, including refractory periods, has been argued to play an important role in the effect of stimulation (37). In the present study, coils in the stimulation device were evenly spaced across the cap and the same stimulation parameters were used for all coils. The signals used were square waves of a given frequency. Future studies could investigate the effect of stimulating with different spatial and temporal patterns. Another important aspect concerns the duration and interval between stimulation sessions. While in the present study stimulation sessions lasted $20 \mathrm{~min}$ and occurred once per week for eight consecutive weeks, in the Thomas et al study (10), two daily 40 min sessions for seven consecutive days were used. Despite the comparatively long interval between sessions, the increase in pain thresholds in the present study was maintained from week to week, except for the period between week 1 and week 2 (Figure 5, upper panel). In fact, the pain threshold increase was roughly sustained for the eight-week trial except for a drop at week 2 and a smaller drop at week 6; therefore, the need for a shorter interval between stimulation sessions is not immediately obvious from the data. Nevertheless, a shorter interval between sessions may produce a larger increase in pain threshold if effects from different sessions are additive. In fact, the decrease in ongoing pain is more gradual, evolving at least until week 7 . This suggests that the neurophysiological mechanisms underlying both types of pain are being affected differently. An alternative explanation, given that the score for chronic pain is subjective, is that patients take some time to internalize changes in symptoms. The other scores that improved with stimulation above a possible placebo effect (ability to perform daily activities and sleep quality; Figure 5), which are also rated subjectively, also improved in a gradual manner. All three of these subjective scores show improvement after week 6 , which suggests that decreasing the number of sessions may reduce the beneficial effect of stimulation.

The main limitation to the present trial was that no follow-up period was included; therefore, it is not possible to establish at present how lasting the beneficial effects of stimulation were. In addition, only female patients from the Andalucia region (southern Spain) were
TABLE 1

Relative changes from baseline and $95 \%$ Cls after eight weeks for all measured outcomes

\begin{tabular}{lcrcr}
\hline & $\begin{array}{c}\text { Stimulation } \\
\text { change }\end{array}$ & $\mathbf{9 5 \%} \mathbf{~ C l}$ & $\begin{array}{c}\text { Sham } \\
\text { change }\end{array}$ & $\mathbf{9 5 \% ~ C l}$ \\
\hline Pain threshold & 28 & 6 to 51 & -10 & -30 to 9 \\
Daily activities & 11 & -9 to 34 & -27 & -45 to -8 \\
Pain intensity & -39 & -50 to -28 & -8 & -25 to 12 \\
Fatigue & -31 & -45 to -19 & -7 & -27 to 13 \\
Anxiety & -34 & -46 to -15 & -12 & -31 to 13 \\
Depression & -45 & -58 to -30 & -16 & -37 to 9 \\
Sleep quality & 75 & 16 to 133 & -24 & -15 to 74 \\
Headaches & -35 & -51 to -18 & -18 & -44 to -10 \\
Serotonin level & -3 & -37 to 27 & -5 & -33 to 30 \\
\hline
\end{tabular}

Data presented as \% unless otherwise indicated.

included. Future studies should include follow-up periods and male patients to check for potential differences in responses. We do not expect the regional distribution to have a noticeable effect in the present results because the presentation of fibromyalgia is similar worldwide.

Neuroimaging studies (19-21) have provided evidence that central system processing of nociceptive signals is affected in FMS. The fact that low-intensity TMS had an effect on symptoms further supports this notion. In fact, Thomas et al (10) found that effects of stimulation were specific to FMS because symptoms of chronic localized musculoskeletal or inflammatory pain patients did not improve after exposure.

Future studies could investigate how changing parameters, such as stimulation duration, interval between sessions, spatiotemporal pattern of stimulation, number of sessions and homogeneity of magnetic fields, affect stimulation efficacy. Further work that includes a follow-up period is also needed to determine how long the improvement in symptoms lasts after the stimulation sessions are discontinued.

\section{CONCLUSIONS}

Results from the present clinical trial show that very low-intensity TMS can have an analgesic and antinociceptive effect when applied to fibromyalgia patients. In addition, improvements in sleep quality and the ability to perform daily activities were also apparent. No adverse effects were reported. Very low-intensity magnetic stimulation may be of benefit for the treatment of chronic pain and other symptoms associated with fibromyalgia, although further research is needed to optimize stimulation parameters.

SOURCES OF FUNDING: The authors thank the Humanism and Science Foundation (Guzman el Bueno 66, 28015 Madrid, Spain) for financial support. Angel Nevado received funding from project PSI201022118 from the Spanish Ministry of Science and Innovation.

DISCLOSURES: Ceferino Maestú is an author of a patent for the magnetic stimulation device used in the present study.

\section{REFERENCES}

1. Calvo AC, Azanza MJ. Synaptic neurone activity under applied $50 \mathrm{~Hz}$ alternating magnetic fields. Comp Biochem Physiol C Pharmacol Toxicol Endocrinol 1999;124:99-107.

2. Bawin SM, Satmary WM, Jones RA, Adey WR, Zimmerman G. Extremely-low-frequency magnetic field disrupt rhythmic slow activity in rat hippocampal slices. Bioelectromagnetics 1996;17:388-95.

3. Prato FS, Kavaliers M, Thomas AW. Extremely low frequency magnetic fields can either increase or decrease analgesia in the land snail depending on field and light conditions. Bioelectromagnetics 2000;4:287-301.

4. Choi YM, Joeng JH, Kim JS, Lee BC, Je HD, Sohn UD. Extremely low frequency magnetic field exposure modulates the diurnal rhythm of the pain threshold in mice. Bioelectromagnetics 2003;24:206-10. 
5. Shupak NM, Hensel JM, Cross-Mellor SK, Kavaliers M, Prato FS, Thomas AW. Analgesic and behavioural effects of a $100 \mathrm{~T}$ specific pulsed extremely low frequency magnetic field on control and morphine treated CF-1 mice. Neurosci Lett 2004;354:30-3.

6. Bao X, Shi Y, Huo X, Song T. A possible involvement of betaendorphin, substance $\mathrm{P}$, and serotonin in rat analgesia induced by extremely low frequency magnetic field. Bioelectromagnetics 2006;27:467-72.

7. Prato FS, Desjardins-Holmes D, Keenliside LD, et al. The detection threshold for extremely low frequency magnetic fields may be below 1000 nT-Hz in mice. Bioelectromagnetics 2011;32:561-9.

8. Sartucci F, Bonfiglio L, Del Seppia C, et al. Changes in pain perception and pain-related somatosensory evoked potentials in humans produced by exposure to oscillating magnetic fields. Brain Res 1997;769:362-6.

9. Shupak NM, McKay JC, Nielson WR, Rollman GB, Prato FS, Thomas AW. Exposure to a specific low frequency magnetic field: A double-blind placebo-controlled study of effects on acute pain ratings in rheumatoid arthritis and fibromyalgia pain populations. Pain Res Manag 2006;11:85-92.

10. Thomas AW, Graham K, Prato FS, et al. A randomized, doubleblind, placebo-controlled clinical trial using a low-frequency magnetic field in the treatment of musculoskeletal chronic pain. Pain Res Manag 2007;12:249-58.

11. Wolfe FW, Smythe HA, Yunas MB, et al. The American College of Rheumatology 1990 criteria for the classification of fibromyalgia. Arthritis Rheum 1990;33:160-72.

12. Bennett RM, Jones J, Turk DC, Russell IJ, Matallana L. An internet survey of 2,596 people with fibromyalgia. BMC Musculoskelet Disord 2007;8:27.

13. Wolfe F, Ross K, Anderson J, Russell IJ, Hebert L. The prevalence and characteristics of fibromyalgia in the general population. Arthritis Rheum 1995;38:19-28.

14. Price DD, Staud R. Neurobiology of fibromyalgia syndrome. J Rheumatol Suppl. 2005;75:22-8.

15. Mahdi AA, Fatima G, Das SK, Verma NS. Abnormality of circadian rhythm of serum melatonin and other biochemical parameters in fibromyalgia syndrome. Indian J Biochem Biophys 2011;48:82-7.

16. Recla JM. New and emerging therapeutic agents for the treatment of fibromyalgia: An update. J Pain Res 2010;3:89-103.

17. Gibson SJ, Littlejohn GO, Gorman MM, Helme RD, Granges G. Altered heat pain thresholds and cerebral event related potentials following painful $\mathrm{CO}_{2}$ laser stimulation in subjects with fibromyalgia syndrome. Pain 1994;58:185-93.

18. Granot M, Buskila D, Granovsky Y, Sprecher E, Neumann L, Yarnitsky D. Simultaneous recording of late and ultra-late pain evoked potentials in fibromyalgia. Clin Neurophysiol 2001;112:1881-87.

19. Gracely RH, Petzke F, Wolf JM, Clauw DJ. Functional magnetic resonance imaging evidence of augmented pain processing in fibromyalgia. Arthritis Rheum 2002;46:1333-43.

20. Desmeules JA, Cedraschi C, Rapiti E, et al. Neurophysiologic evidence for a central sensitization in patients with fibromyalgia. Arthritis Rheum 2003;48:1420-9.
21. Burgmer M, Pogatzki-Zahn E, Gaubitz M, Wessoleck E, Heuft G, Pfleiderer B. Altered brain activity during pain processing in fibromyalgia. Neuroimage 2009;44:502-8.

22. Lorenz J, Grasedyck K, Bromm B. Middle and long latency somatosensory evoked potentials after painful laser stimulation in patients with fibromyalgia syndrome. Electroencephalogr Clin Neurophysiol 1996;100:165-8.

23. Montoya P, Sitges C, García-Herrera M, et al. Reduced brain habituation to somatosensory stimulation in patients with fibromyalgia. Arthritis Rheum 2006;54:1995-2003.

24. Sampson SM, Rome JD, Rummans TA. Slow-frequency rTMS reduces fibromyalgia pain. Pain Med 2006;7:115-8.

25. Passard A, Attal N, Benadhira R, et al. Effects of unilateral repetitive transcranial magnetic stimulation of the motor cortex on chronic widespread pain in fibromyalgia. Brain 2007;130:2661-70.

26. Carretero B, Martin MJ, Juan A, et al.Low-frequency transcranial magnetic stimulation in patients with fibromyalgia and major depression. Pain Med 2009;10:748-53.

27. Mhalla A, Baudic S, Ciampi de Andrade D, et al. Long-term maintenance of the analgesic effects of transcranial magnetic stimulation in fibromyalgia. Pain 2011;152:1478-85.

28. Short EB, Borckardt JJ, Anderson BS, et al.Ten sessions of adjunctive left prefrontal rTMS significantly reduces fibromyalgia pain: A randomized, controlled pilot study. Pain 2011;152:2477-84

29. Marlow NM, Bonilha HS, Short EB. Efficacy of transcranial direct current stimulation and repetitive transcranial magnetic stimulation for treating fibromyalgia syndrome: A systematic review. Pain Pract 2013;13:131-45.

30. Maestú C, Álvarez R, del Pozo F. Transcranial stimulator for low intensity, has series of brain stimulation coils to circulate current that generates stimulator magnetic field, and signal flow is generated by digital microcontroller. Patent number EP2371274 A1. 2011.

31. Jasper HH. Report of the Committee on Methods of Clinical Examination in Electroencephalography. Electroenceph Clin Neurophysiol 1958;10:370-1.

32. Burckhardt CS, Clark SR, Bennett RM. The fibromyalgia impact questionnaire: Development and validation. J Rheumatol 1991;5:728-33

33. Kavaliers M, Ossenkopp KP. Opioid systems and magnetic field effects in the land snail, Cepaea nemoralis. Biol Bull 1991;180:301-9.

34. Prato FS, Carson JJ, Ossenkopp KP, Kavaliers M. Possible mechanisms by which extremely low frequency magnetic fields affect opioid function. FASEB J 1995;9:807-14.

35. Engström S, Fitzsimmons R. Five hypotheses to examine the nature of magnetic field transduction in biological systems. Bioelectromagnetics 1999;20:423-30.

36. Del Seppia C, Ghione S, Luschi P, Ossenkopp KP, Choleris E, Kavaliers M. Pain perception and electromagnetic fields. Neurosci Biobehav Rev 2007;31:619-42.

37. Thomas AW, Drost DJ, Prato FS. Human subjects exposed to a specific pulsed (200 microT) magnetic field: Effects on normal standing balance. Neurosci Lett 2001;297:121-4. 


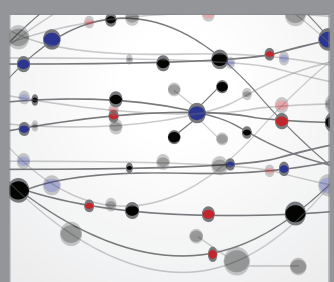

The Scientific World Journal
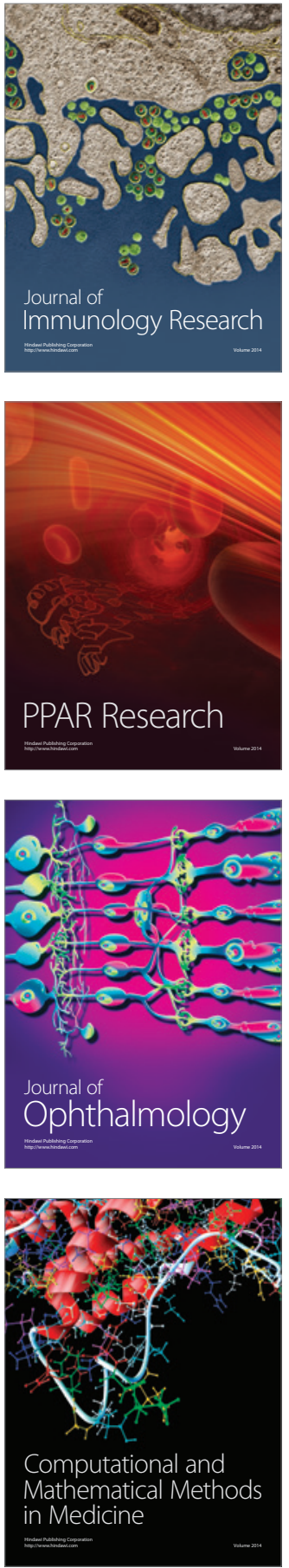

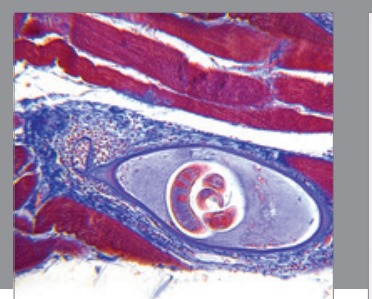

Gastroenterology Research and Practice

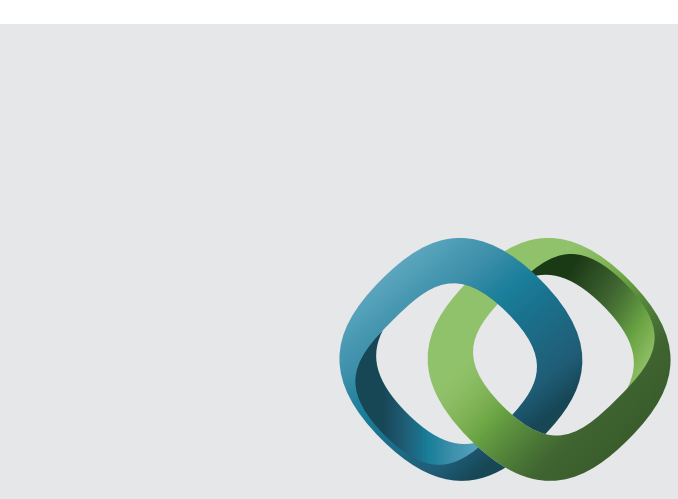

\section{Hindawi}

Submit your manuscripts at

http://www.hindawi.com
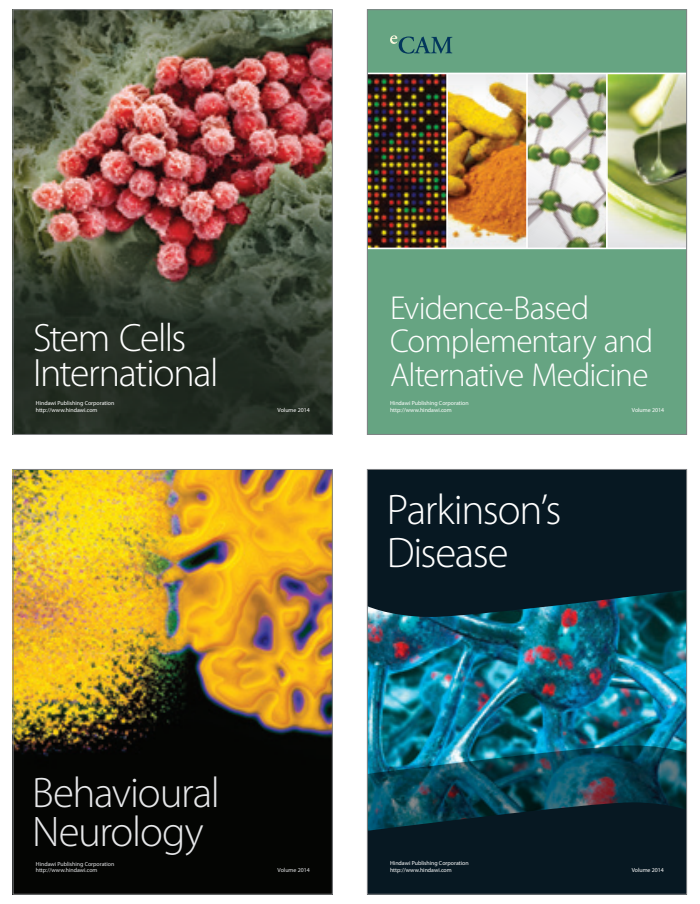
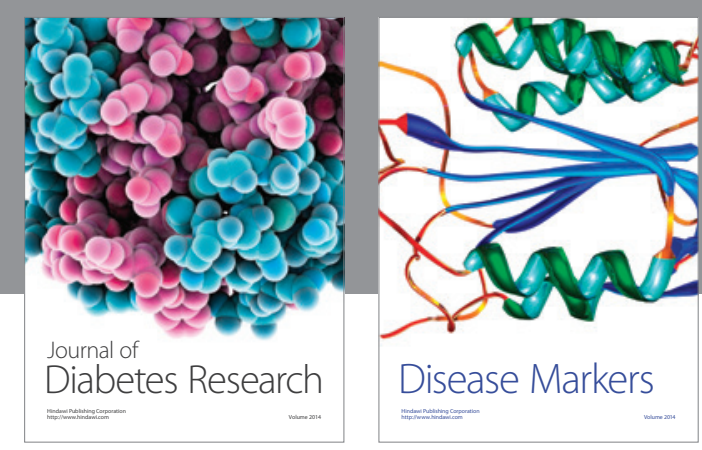

Disease Markers
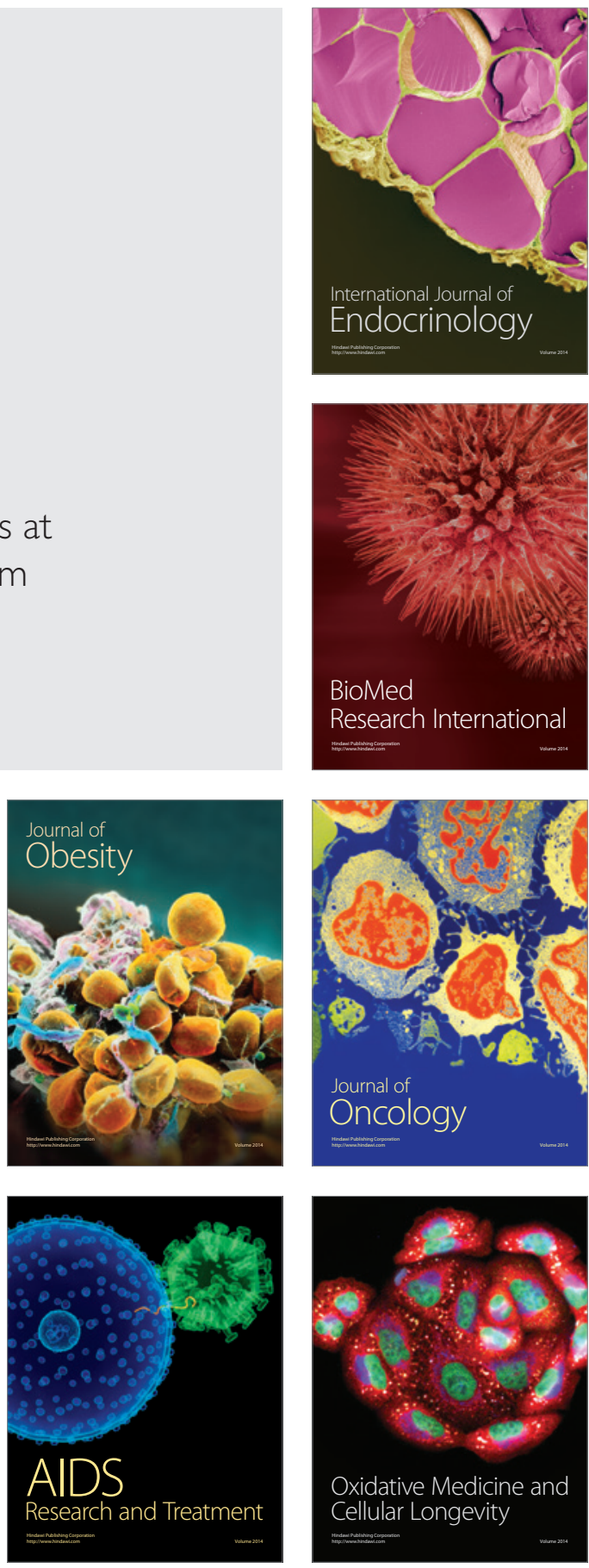